\title{
Clinical and endoscopic evaluation in patients with gastroesophageal symptoms
}

\author{
Aimée Teixeira dos Santos MEIRA, Davi TANAJURA and Irineu dos Santos VIANA
}

Received 6/11/2018

Accepted 13/3/2019

ABSTRACT - Background - The gastroesophageal reflux disease (GERD) is the most common esophageal disease in medical practice, and it is suspected according to patients' symptoms. GERD can be classified in erosive esophagitis (EE) according to the presence of upper gastrointestinal endoscopy findings. Objective - To evaluate endoscopic findings in patients with symptoms suggestive of GERD comparing epicemiological and risk factors. Methods - Upper endoscopy reports were examined retrospectively from patients with symptoms of GERD such as heartburn, regurgitation, cough, throat clearing, globus and chest pain. EE was determined based on Los Angeles classification. Comparisons between risk factors in EE and non-EE groups were done with statistical analysis. Results - A total of 984 endoscopic reports were examined and 676 selected for analysis (281 with EE and 395 with non-EE form). Most were female $381(56.36 \%)$ with a mean age of $44.01 \pm 15.40$ years. Hiatal hernia was present in $47(6.96 \%)$ and smoking in $41(6.07 \%)$. Univariate logistic regression showed that male $(\mathrm{OR}=2.24, \mathrm{CI} 95 \%, 1.63-3.06)$ and hiatal hernia $(\mathrm{OR}=4.52, \mathrm{CI} 95 \%, 2.30-8.89)$ were independent predictors of erosions in the EE group. The presence of hiatal hernia $(\mathrm{OR}=12.04, \mathrm{CI} 95 \%, 3.57-40.62)$, smoking $(\mathrm{OR}=8.46, \mathrm{CI} 95 \%, 3.28$ 31.32) and aged patients ( $\mathrm{OR}=8.01$, CI 95\%, 2.42-26.49) were also indicated as a risk factor for severe EE (grades C and D of Los Angeles). Conclusion - Male gender and hiatal hernia were associated with EE. Aged patients, smoking and hiatal hernia were related to severe EE. It is suggested that the risk factors for EE and non-EE types are different. Cohort studies are necessary to identify the exact mechanisms involved in each disease form. HEADINGS - Gastroesophageal reflux. Peptic esophagitis. Hiatal hernia. Endoscopy. Epidemiology.

\section{INTRODUCTION}

The gastroesophageal reflux disease (GERD) is the most common esophageal disease in medical practice. It is defined as a condition that develops when reflux of gastric contents causes uncomfortable symptoms and/or complications ${ }^{(1)}$. It is estimated that the GERD prevalence in Brazil is approximately 7.3\% when the general population is evaluated ${ }^{(2)}$.

The pathophysiology of GERD is multifactorial, marked by the pathological return of harmful agents such as hydrochloric acid, pepsin, bile salts and pancreatic enzymes to the esophagus. To have such exposure, it is necessary to compromise the anti-reflux barrier and reduce esophageal clearance ${ }^{(3)}$. Among the changes in the barrier, the transient relaxation of the lower esophageal sphincter (IES) is the most relevant. Although GERD progresses favorably in most cases, complications such as esophageal bleeding, ulcers, stenosis and Barrett's esophagus can occur.

Gastroesophageal symptoms are common referred in the evaluation of suspected GERD such as heartburn and regurgitation. The diagnosis method of GERD complications is upper endoscopy (EGD), indicated in the presence of signs and symptoms of alarm or in the absence of response to empirical treatment ${ }^{(4)}$. When performed, EGD also allows to divide GERD into two large groups: erosive and non-erosive ${ }^{(5)}$.

An important topic of research is the attempt to compare risk factors and findings in EGD. Studies on gastroesophageal symptoms in the Brazilian population are necessary to define the exact correlations between epidemiological, clinical and endoscopic data. The present study aims to evaluate the endoscopic findings of patients with gastroesophageal symptoms and compare them with epidemiology and risk factors.

\section{METHODS}

This is a retrospective, cross-sectional study based on reports of pre-endoscopic evaluations recorded in charts and endoscopic exams performed from 2007 to 2016 in a private practice in Brumado, Bahia.

Endoscopies were requested by gastroenterologists, pulmonologists, otorhinolaryngologists, cardiologists, hematologists, surgeons and general practitioners and performed with a Pentax EPK-1000 video endoscope by a single examiner (ISV).

Patients with complaints of heartburn, regurgitation, globus, frequent clearing the throat, dysphonia, chronic dry cough and atypical chest pain were used as inclusion criteria. Patients younger than 18 years of age, history of gastrointestinal tract surgery, gastrointestinal malignancy, use of antisecretory medication the week prior to EGD, hematemesis, melena, pregnancy, Barrett's esophagus or controls of Helicobacter pylori eradication were excluded. In this study gastroesophageal reflux disease (GERD) was suspected indirectly based only on clinical findings (gastroesophageal symptoms).

The chart used during pre-endoscopic evaluation included patient data such as gender, age, smoking, alcohol consumption, use of non-steroidal anti-inflammatory drugs (NSAID), use of antisecretory medication and presence of associated comorbidities. Elderly people were defined as patients with more than 60 years. 
Endoscopic reports described the presence or absence of lesions, such as gastritis, ulcers, duodenitis, neoplasms, esophagitis, hiatal hernia, gastric polyps, among others. Erosive esophagitis was diagnosed by the presence of erosive lesions on the esophageal mucosa according to the Los Angeles classification, subdivided into A (one or more erosions less than $5 \mathrm{~mm}$ in length, not continuous), B (at least one erosion greater than $5 \mathrm{~mm}$, not continuous), $\mathrm{C}$ (continuous erosions involving less than $75 \%$ of the circumference of the esophagus) and D (continuous erosions involving more than $75 \%$ of the circumference of the esophagus) ${ }^{(6)}$. The presence of hiatal hernia was considered when the esophagogastric transition was 2 $\mathrm{cm}$ or more above the diaphragmatic clamping. Non-erosive group was defined by the absence of endoscopic findings in this study.

Ethical approval of this study was obtained by the research ethics committee of the Universidade Estadual do Sudoeste da Bahia (UESB) (number 069609/2016). Subsequently data were analyzed using Small Stata 3.0. Categorical variables were described in total numbers and percentages, and the continuous variables in means and standard deviation. Student's $t$-test was used to compare continuous variables and chi-square test for categorical variables. Univariate and multivariate logistic regression analysis was applied for each factor, with a $95 \%$ confidence interval (CI) for odds ratio (OR). A value of $P<0.05$ was considered statistically significant.

\section{RESULTS}

A total of 984 patients with clinical symptoms compatible with GERD were evaluated and 676 of these were chosen for analysis after exclusion criteria applied. Erosive esophagitis (EE) was found in $281(42 \%)$ patients, while $395(58 \%)$ had non-erosive findings. Among the erosive form grades A or B of Los Angeles were present in $269(96 \%)$, while grades C or D in $12(4 \%)$ individuals (FIGURE 1).

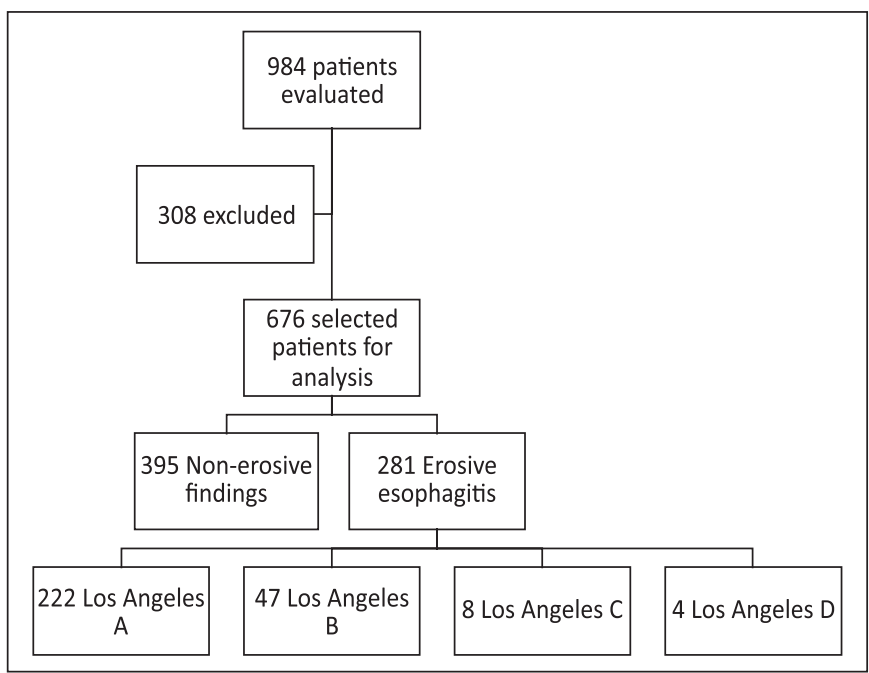

FIGURE 1. Patients selection.

Indications for endoscopy were variated, being "reflux" the most common $608(90 \%)$, followed by retrosternal pain/burning $34(5 \%)$, globus $25(3.7 \%)$ and pyrosis $9(1.3 \%)$. The majority of the 676 selected patients were female $381(56.36 \%)$ with a mean age of $44.01 \pm 15.40$ years. Hiatal hernia was present in $47(6.96 \%)$ and smoking in $41(6.07 \%)$.
When epidemiological date was evaluated (TABLE 1) a predominance of males was found in EE group in relation to patients with non-erosive disease ( 54.4 vs $35.5 \%)$, with statistical difference $(P<0.001)$. No age difference was fond between the groups $(P=0.57)$. Risk factors as smoking and alcohol use were observed in the two groups with no differences. Also, no divergence was found when comparing the presence of comorbidities such as systemic arterial hypertension, coronary disease, pneumopathies, diabetes, dyslipidemias, renal dysfunction and inflammatory diseases. The proportion of patients taking ASA or NSAIDs was similar in both groups. Hiatal hernia was seen in $12(3.1 \%)$ patients in the non-erosive group and $35(12.5 \%)$ in EE group $(P<0.001)$.

TABLE 1. Epidemiological and clinical characteristics in the studied population according to endoscopic finding.

\begin{tabular}{lccc}
\hline & $\begin{array}{c}\text { Non-erosive group } \\
(\mathbf{n}=385)\end{array}$ & $\begin{array}{c}\text { EE group } \\
(\mathbf{n}=281)\end{array}$ & $\boldsymbol{P}$ \\
\hline Age mean (SD) & $44.48 \pm 15.52$ & $43.62 \pm 15.24$ & $0.57^{\mathrm{a}}$ \\
Gender n (\%) & & & \\
$\quad$ Female & $252(64.45)$ & $129(45.26)$ & $<0.001^{\mathrm{b}}$ \\
$\quad$ Male & $139(35.55)$ & $156(54.74)$ & \\
Smoking & $20(5.12)$ & $21(7.32)$ & $0.22^{\mathrm{b}}$ \\
Alcohol use & $130(33.25)$ & $105(36.84)$ & $0.32^{\mathrm{b}}$ \\
Comorbidities & $109(27.88)$ & $75(26.32)$ & $0.65^{\mathrm{b}}$ \\
NSAIDs use & $70(17.95)$ & $45(15.85)$ & $0.47^{\mathrm{b}}$ \\
Hiatal hernia & $12(3.05)$ & $35(12.46)$ & $<0.001^{\mathrm{b}}$ \\
\hline $\begin{array}{l}{ }^{\mathrm{a}} \text { Student t test; }{ }^{\mathrm{b}} \text { chi-square test. EE: erosive esophagitis; NSAID: non-steroidal anti- } \\
\text { inflammatory drugs. }\end{array}$ & & &
\end{tabular}

In analysis with univariate logistic regression male gender $(\mathrm{OR}=2.24(1.63-3.06)$ and hiatal hernia $(\mathrm{OR}=4.52,95 \% \mathrm{CI}, 2.30$ 8.89) appeared to increase the risk of EE (TABLE 2). Applying multivariate logistic regression those two variables remained as independent risk factors [male gender OR 2.22 (IC95\%1.61-3.05) and hiatal hernia OR 4.49 (IC95\% 2.26-8.91)].

TABLE 2. Univariate logistic regression - OR with 95\% CI for EE risk.

\begin{tabular}{lcc}
\hline Risk factors & OR $(95 \%$ CI $)$ & $\boldsymbol{P}$ \\
\hline Age $>60$ years & $0.87(0.58-1.30)$ & 0.50 \\
Male gender & $2.24(1.63-3.06)$ & $<0.001$ \\
Smoking & $1.24(0.65-2.39)$ & 0.50 \\
Alcohol use & $0.88(0.61-1.25)$ & 0.47 \\
Comorbidities & $1.05(0.73-1.53)$ & 0.72 \\
NSAIDs & $0.82(0.54-1.25)$ & 0.36 \\
Hiatal hernia & $4.52(2.30-8.89)$ & $<0.001$ \\
\hline OR: odds ratio; EE: erosive esophagitis; NSAID: non-steroidal anti-inflammatory drugs.
\end{tabular}

When considered only severe EE degrees (C or D of Los Angeles) logistic regression confirmed hiatal hernia as an independent predictor $(\mathrm{OR}=12.04,95 \% \mathrm{CI}, 3.57-40.62)$. Additionally, aged people $(\mathrm{OR}=12.04,95 \% \mathrm{CI}, 2.42-26.49)$ and smoking history $(O R$ $=8.4695 \%$ CI 2.28-31.32) also appeared as significant risk factors to severe EE (TABLE 3). Males did not appear as a risk factor for grades $\mathrm{C}$ or $\mathrm{D}$ in this study. 
TABLE 3. Univariate logistic regression - OR with 95\% CI for high grade EE (Los Angeles C and D).

\begin{tabular}{lcc}
\hline Risk factors & OR $(95 \%$ CI $)$ & $\boldsymbol{P}$ \\
\hline Age $>$ 60 years & $8.01(2.42-26.49)$ & $<0.001$ \\
Male gender & $1.65(0.48-5.64)$ & 0.42 \\
Smoking & $8.46(2.28-31.32)$ & $<0.001$ \\
Alcohol use & $1.32(0.74-2.35)$ & 0.34 \\
Comorbidities & $0.54(0.11-2.55)$ & 0.34 \\
NSAIDs & $1.9(0.49-7.32)$ & 0.35 \\
Hiatal hernia & $12.04(3.58-40.51)$ & $<0.001$ \\
\hline
\end{tabular}

OR: odds ratio; EE: erosive esophagitis; NSAID: non-steroidal anti-inflammatory drugs.

\section{DISCUSSION}

The present study reported a prevalence of $42 \%$ of EE findings in endoscopy among patients with symptoms suggestive of GERD. When classification criteria was applied, mild forms were more prevalent (96\% of grade A or B of Los Angeles). These findings are consistent with others in literature ${ }^{(7)}$.

In this study male gender and the presence of hiatal hernia were independent risk factors for the erosive endoscopic form. Similarly, one work ${ }^{(8)}$ evaluated 792 patients, finding men and the presence of hernia as predictors of erosion in endoscopy. Another large study ${ }^{(9)}$ showed a higher prevalence of male patients $(59 \%)$ and a hiatal hernia $(56 \%)$ in the EE group.

A relationship between the presence of hiatal hernia and the severe erosive forms (Los Angeles C and D) was also observed in this study. A Chinese investigation ${ }^{(10)}$ found significant association of hiatal hernia in the endoscopic findings of severe EE. This may indicate the great participation of the sphincter function in the pathophysiology and evolution of the disease, since the hernia reduces the pressure of the lower esophageal sphincter (LES). Moreover, patients with cranial slip of LES are more susceptible to a higher frequency of transient relaxation and more episodes of reflux during swallowing ${ }^{(11,12)}$. There is also a relationship between hernia size and esophagitis, being the first a predictor of lesion severity ${ }^{(13)}$.

Currently, obesity is indicated as a contributing condition for the pathophysiology of GERD, since excess weight may increase intra-abdominal pressure and, consequently, intragastric pressure, gastroesophageal pressure gradient and the possibility of hiatal hernia $^{(14)}$. However, the association between obesity and erosive esophagitis remains controversial. Kim et al. ${ }^{(15)}$ concluded that the $\mathrm{BMI} \geq 25$ is a risk factor for EE. On the other hand, one study in Korea $^{(8)}$ showed that this BMI value, in a multivariate analysis, is not a risk factor, whereas the hernia is statistically associated with the erosive form. Biccas et al. ${ }^{(16)}$ observed a significantly higher prevalence of hiatal hernia in EE patients, but did not attribute this increase to overweight. Thus, although obesity leads to a greater possibility of hiatal hernia, it does not seem to influence the role of the hernia as a predictor of severity in EGD. The present study did not report the patients' BMI and its association with hernia but found the latter as an independent risk factor for EE.

Although the study did not saw male sex as a risk factor for severe esophagitis, other analyzes had this finding. A large study of 6,709 patients showed that male gender, obesity, and duration of heartburn were independent predictors for the Los Angeles C and $\mathrm{D}$ grades ${ }^{(17)}$. Labenz et al. ${ }^{(18)}$ also found a higher risk of severe erosion in men. A meta-analysis showed that males predominated in the group of patients with Barrett's esophagus and esophageal adenocarcinoma $^{(19)}$.

There was no positive correlation of aging with EE, but there was a correlation in severe EE group. Fujiwara et al. ${ }^{(5)}$ noted a higher prevalence of older ages in EE patients, but there was no statistical difference between groups. The univariate analysis of $\mathrm{Wu}$ et al. ${ }^{(10)}$ found age as a predictor of erosive esophagitis, however this was not ratified after multivariate analysis. It was found in this study that the prevalence of hiatal hernia and esophageal dysmotility increased with age, causing a confounding factor. One study in Asia have demonstrated a positive association of aging and $\mathrm{EE}^{(20)}$. In other analysis 6,215 patients were evaluated and aging was associated with high risk for severe EE in a multivariate assessment ${ }^{(18)}$.

There were no statistical differences in the effects of alcohol and smoking on endoscopic manifestations in EE group, but smoking appeared as risk factor for severe EE. Alcohol has been identified as a risk condition for erosion in some studies. Anderson et al. ${ }^{(21)}$ showed that alcohol consumption from the onset of adulthood may increase EE risk. A large Japanese study, with 10,837 patients, observed smoking and alcoholism as independent factors for esophageal mucosal erosions ${ }^{(22)}$ its risk factors are still a subject of controversy. This is probably due to inadequate distinction between reflux esophagitis (RE. In the ProGERD study ${ }^{(18)}$ alcohol and tobacco were predictors of severe esophagitis (Los Angeles C and D). In contrast, other studies found no differences between EE and non-EE groups ${ }^{(8,23)}$. In the present study alcohol and tobacco use was slightly more prevalent in the EE group but it lacks significance, possible due small sentence and underreport.

No differences were found between comorbidities and EE and non-EE groups. This finding was consistent with the ProGERD ${ }^{(18)}$, which evaluated the influence of hypertension, coronary disease, circulatory changes, diabetes, lung and inflammatory diseases in two forms of GERD. Li et al. ${ }^{(23)}$ also evaluated the participation of hypertriglyceridemia, hypercholesterolemia, low levels of HDL, high levels of LDL and glycated hemoglobin, and found no statistical difference between the groups. This same study did not consider the use of NSAIDs/ASA as a predictor of EE. Such finding is consistent with the results described herein.

\section{CONCLUSION}

Almost half of patients had a EE finding in endoscopy and lighter forms prevailed (Los Angeles A and B). Male sex and the presence of hiatal hernia were associated with EE. In addition, hiatal hernia, aging and smoking was correlated to the most severe grades of EE (Los Angeles C and D). It is suggested that the risk factors for $\mathrm{EE}$ and non-erosive forms are different. Further studies are needed to identify the aspects and mechanisms involved in each classification.

\section{Authors' contribution}

Meira ATS: data collection, survey execution, writing of text. Tanajura D: statistical analysis, writing of text. Viana IS: data collection, survey execution.

\section{Orcid}

Aimée Teixeira dos Santos Meira. Orcid: 0000-0002-7489-1497.

Davi Tanajura. Orcid: 0000-0002-4583-2391.

Irineu dos Santos Viana. Orcid: 0000-0002-7255-4657. 
Meira ATS, Tanajura D, Viana IS. Avaliação clínica e endoscópica em pacientes com sintomas gastroesofágicos. Arq Gastroenterol. 2019;56(1):51-4.

RESUMO - Contexto - A doença do refluxo gastroesofágico (DRGE) é uma das doenças digestivas mais comuns na prática médica e deve ser suspeitada de acordo com os seus sintomas clínicos, podendo ser classificada em esofagite erosiva (EE) de acordo com os achados de endoscopia. Objetivo - Avaliar os achados endoscópicos em pacientes com sintomas sugestivos de DGRE comparando fatores de risco e epidemiológicos. Métodos - Resultados de endoscopias digestiva foram examinados retrospectivamente de pacientes com sintomas relacionados com DRGE como pirose, regurgitação, tosse, pigarro, globus e dor torácica. EE foi determinada de acordo com a classificação de Los Angeles. Comparação de fatores de risco entre os grupos EE e não-EE foram feitos com análise estatística. Resultados - Um total de 984 endoscopias foram examinadas e 676 endoscopias selecionadas para análise (281 com EE e 395 sem EE). A maioria dos pacientes era do sexo feminino 381 (56,36\%) com uma idade média de 44,01士15,40 anos. Hérnia hiatal esteve presente em 47 (6,96\%) e tabagismo em 41 (6,07\%). Regressão logística uni variada mostrou que sexo masculino (OR=2,24 - IC 95\%: 1,63-3,06) e hérnia hiatal (OR=4,52 - CI 95\%: 2,30-8,89) foram fatores de risco independentes de EE. A presença de hérnia hiatal (OR=12,04 - CI 95\%: 3,57-40,62), tabagismo (OR=8,46 - CI 95\%: 3,28-31,32) e pacientes idosos (OR=8,01 - CI 95\%, 2,42-26,49) foram fatores de risco no grupo de EE grave (classes C e D de Los Angeles). Conclusão - Sexo masculino e hérnia hiatal foram associados com EE. Idade avançada, tabagismo e hérnia hiatal foram relacionados à forma grave de EE. É sugerido que os fatores de risco de pacientes com e sem EE sejam diferentes. Estudos de coorte são necessários para identificar os mecanismos exatos envolvidos em cada forma da doença.

DESCRITORES - Refluxo gastroesofágico. Esofagite péptica. Hérnia hiatal. Endoscopia. Epidemiologia.

\section{REFERENCES}

1. Vakil N, van Zanten S V, Kahrilas P, Dent J, Jones R, Global Consensus Group The Montreal definition and classification of gastroesophageal reflux disease: a global evidence-based consensus. Am J Gastroenterol. 2006;101:1900-20; quiz 1943.

2. Moraes-Filho JPP, Chinzon D, Eisig JN, Hashimoto CL, Zaterka S. Prevalence of heartburn and gastroesophageal reflux disease in the urban Brazilian population. Arq Gastroenterol. 2005;42:122-7.

3. Tack J, Pandolfino JE. Pathophysiology of Gastroesophageal Reflux Disease. Gastroenterology. 2018;154:277-88.

4. Katz PO, Gerson LB, Vela MF. Guidelines for the Diagnosis and Management of Gastroesophageal Reflux Disease. Am J Gastroenterol. 2013;108:308-28.

5. Fujiwara Y, Higuchi K, Shiba M, Yamamori K, Watanabe Y, Sasaki E, et al. Differences in Clinical Characteristics between Patients with Endoscopy-Negative Reflux Disease and Erosive Esophagitis in Japan. Am J Gastroenterol. 2005;100:754-8.

6. Sami S, Ragunath K. The Los Angeles Classification of Gastroesophageal Reflux Disease. Video J Encycl GI Endosc. 2013;1:103-4.

7. Li W, Zhang ST, Yu ZL. Clinical and endoscopic features of Chinese reflux esophagitis patients. World J Gastroenterol. 2008;14:1866-71.

8. Ha NR, Lee HL, Lee OY, Yoon BC, Choi HS, Hahm JS, et al. Differences in Clinical Characteristics between Patients with Non-Erosive Reflux Disease and Erosive Esophagitis in Korea. J Korean Med Sci. 2010;25:1318.

9. Carlsson R, Dent J, Watts R, Riley S, Sheikh R, Hatlebakk J, et al. Gastro-oesophageal reflux disease in primary care: an international study of different treatment strategies with omeprazole. International GORD Study Group. Eur J Gastroenterol Hepatol. 1998;10:119-24.

10. Wu JCY, Cheung CMY, Wong VWS, Sung JJY. Distinct Clinical Characteristics Between Patients With Nonerosive Reflux Disease and Those With Reflux Esophagitis. Clin Gastroenterol Hepatol. 2007;5:690-5.

11. Kahrilas PJ, Shi G, Manka M, Joehl RJ. Increased frequency of transient lower esophageal sphincter relaxation induced by gastric distention in reflux patients with hiatal hernia. Gastroenterology. 2000;118:688-95.

12. van Herwaarden MA, Samsom M, Smout AJ. Excess gastroesophageal reflux in patients with hiatus hernia is caused by mechanisms other than transient LES relaxations. Gastroenterology. 2000;119:1439-46.
13. Jones MP, Sloan SS, Rabine JC, Ebert CC, Huang C-F, Kahrilas PJ. Hiatal hernia size is the dominant determinant of esophagitis presence and severity in gastroesophageal reflux disease. Am J Gastroenterol. 2001;96:1711-7.

14. Barak N, Ehrenpreis ED, Harrison JR, Sitrin MD. Gastro-oesophageal reflux disease in obesity: pathophysiological and therapeutic considerations. Obes Rev. 2002;3:9-15.

15. Kim N, Lee SW, Cho SI, Park CG, Yang CH, Kim HS, et al. The prevalence of and risk factors for erosive oesophagitis and non-erosive reflux disease: a nationwide multicentre prospective study in Korea. Aliment Pharmacol Ther. 2007;27:173-85.

16. Biccas BN, Lemme EMO, Abrahão Jr. LJ, Aguero GC, Alvariz Â, Schechter RB. Maior prevalência de obesidade na doença do refluxo gastroesofagiano erosiva. Arq Gastroenterol. 2009;46:15-9.

17. El-Serag HB, Johanson JF. Risk factors for the severity of erosive esophagitis in Helicobacter pylori-negative patients with gastroesophageal reflux disease. Scand J Gastroenterol. 2002;37:899-904.

18. Labenz J, Jaspersen D, Kulig M, Leodolter A, Lind T, Meyer-Sabellek W, et al. Risk Factors for Erosive Esophagitis: A Multivariate Analysis Based on the ProGERD Study Initiative. Am J Gastroenterol. 2004;99:1652-6.

19. Cook MB, Wild CP, Forman D. A Systematic Review and Meta-Analysis of the Sex Ratio for Barrett's Esophagus, Erosive Reflux Disease, and Nonerosive Reflux Disease. Am J Epidemiol. 2005;162:1050-61.

20. Ang TL, Fock KM, Ng TM, Teo EK, Chua TS, Tan J. A comparison of the clinical, demographic and psychiatric profiles among patients with erosive and non-erosive reflux disease in a multi-ethnic Asian country. World J Gastroenterol. 2005;11:3558-61.

21. Anderson LA, Cantwell MM, Watson RGP, Johnston BT, Murphy SJ, Ferguson HR, et al. The Association Between Alcohol and Reflux Esophagitis, Barrett's Esophagus, and Esophageal Adenocarcinoma. Gastroenterology. 2009;136:799-805.

22. Minatsuki C, Yamamichi N, Shimamoto T, Kakimoto H, Takahashi Y, Fujishiro $\mathrm{M}$, et al. Background factors of reflux esophagitis and non-erosive reflux disease: a cross-sectional study of 10,837 subjects in Japan. PLoS One. 2013;8:e69891.

23. Li CH, Hsieh TC, Hsiao TH, Wang PC, Tseng TC, Lin HH, et al. Different risk factors between reflux symptoms and mucosal injury in gastroesophageal reflux disease. Kaohsiung J Med Sci. 2015;31:320-7. 